\title{
How Do I Regret Thee? Let Me Count My Alternatives: Regret and Decision Making in Intimate Relationships
}

\author{
Richard E. Mattson, Ana M. Franco-Watkins, Karlene Cunningham \\ Department of Psychology, Auburn University, Auburn, USA \\ Email: rmattson@auburn.edu
}

Received June $14^{\text {th }}, 2012$; revised July $12^{\text {th }}, 2012$; accepted August $10^{\text {th }}, 2012$

\begin{abstract}
It is unsurprising when dissatisfied couples separate, but happy couples also dissolve their relationship. A hypothesized precursor to such outcomes is the availability of a better alternative partner. The current study examined regret over one's current partner selection as the possible mechanism by which better alternatives leads to partner switching in otherwise happy unions. An undergraduate sample $(\mathrm{N}=94)$ was administered several questionnaires; which included measures of partner regret, relationship satisfaction, the availability of more attractive alternative partners, and the probability of switching to an alternative in the future. For relatively satisfied individuals, the presence of a better alternative elicited regrets about their currently selected partner that, in turn, predicted greater hypothetical intentions to partner switch. Less satisfied individuals also endorsed partner regret, but irrespective of whether a current alternative was actually available. Only relatively satisfied individuals without more attractive alternatives endorsed low partner regret and, subsequently, greater intentions to remain in their current relationship.
\end{abstract}

Keywords: Regret; Intimate Relationships; Decision Making; Social Exchange; Attractive Alternatives; Relationship Satisfaction

\section{Introduction}

It is common to compare one's actual choices with real or imagined alternatives. One potential consequence of this comparison process is regret: A negative affective experience that ensues when one's choice is viewed as less favorable than possible or hypothesized alternatives (Zeelenberg \& Pieters, 2009). Though aversive, the emotional salience of experienced regret may lead to improved decision making in the future. Specifically, it can help prevent the same mistakes from recurring and may direct people to conceivably better alternative options in future situations (see Roese \& Summerville, 2005).

The phenomenon of regret is relevant to many areas of psychological research, especially those that involve decision making. Indeed, studies demonstrate the influence of regret on important choices ranging from financial (De Bondt \& Thaler, 1994) to health-care decisions (Brehaut et al., 2003), as well as on consumer behavior (Tsiros \& Mittal, 2000). However, regrets pertaining to intimate partner decision making remain mostly unexplored. This is somewhat surprising given that decisions about romantic partnerships are some of the most impactful choices individuals make. Moreover, romantic relationships are reported amongst people's biggest regrets (Roese \& Summerville, 2005). It is also notable that the putative mechanism underlying many stay-leave decisions in romantic relationships is the same comparative judgment that leads to the experience of regret. Namely, the comparison between one's current partner and a more attractive alternative is one of the primary determinants of relationship instability [see Levinger (1965) for a theoretical account; and Le \& Agnew (2003) for empirical support].

If experienced regret influences stay-leave decisions in intimate relationships, then its integration into models of relation- ship decision making may provide new and complimentary directions for research. The present study explored whether the presence of a more attractive alternative underscored intentions to partner switch by eliciting partner regret in otherwise satisfied individuals. Also, for those without any current alternatives, it was examined whether lower (versus higher) levels of relationship satisfaction led to more (versus less) partner regret and, consequently, greater hypothetical intentions to switch partners in the future. The proceeding section is a focused primer on social exchange theory (Thibaut \& Kelley, 1959) - the basis for contemporary thinking on relationship decision making. Subsequently, these concepts are integrated with contemporary models of regret, from which are derived specific hypotheses about how and under what circumstances partner regret might influence intimate partner decision making.

\section{The Social Exchange Model of Partner Decision Making}

Thibaut and Kelley (1959) hypothesized that individuals evaluate the quality of their relationship against two criteria. The first is the comparison level (CL): "The standard by which the person evaluates the rewards and costs of a given relationship in terms of what [s] he feels [s] he "deserves"' (Thibaut \& Kelley, 1959: p. 21). Deriving from this basis is the construct of relationship satisfaction; a subjective estimation of the difference between an individual's idiosyncratic cost-benefit standard (i.e., the CL) and the relationship's actual outcomes. Note that the $\mathrm{CL}$ is akin to an individual's expectations (e.g., McNulty \& Karney, 2002), whereas satisfaction concerns the confirmation or disconfirmation of expectations for better or worse (e.g., Fletcher, Simpson, Thomas, \& Giles, 1999).

Dissatisfied individuals (i.e., those experiencing outcomes 
below expectations) do not necessarily dissolve their relationship. Rather, this decision is also contingent upon the perceived cost-benefit ratio of other available partners, which is the second criterion for evaluating the relationship termed the comparison level for alternatives $\left(\mathrm{CL}_{\mathrm{alt}}\right)$. Even dissatisfied individuals will maintain their current relationship if the quality of its outcomes (e.g., sexual satisfaction, social support, etc.) still exceeds those obtainable elsewhere. The $\mathrm{CL}_{\text {alt }}$ is also relevant to relationships in which an individual is satisfied. Specially, except when significant barriers to dissolution are present (e.g., financial dependence), satisfied individuals will also opt in favor of some alternative partnership if they believe it will confer more favorable relationship outcomes (Levinger, 1965). Taken together, irrespective of how satisfied a person is with his or her relationship, if the "present... partnership is strikingly less favorable than the alternatives, he or she will opt for one of the alternatives if the cost of the exchange (barrier) does not obliterate the advantage to be obtained" (Urdy, 1981: p. 889).

\section{Regret in Stay-Leave Decisions}

Recent studies on relationship decision making have mainly focused on relationship-maintaining phenomena typically referred to as commitment devices (e.g., Gonzaga, Haselton, Smurda, Davies, \& Poore, 2008). Commitment devices comprise various affective responses (e.g., love; Maner et al., 2008) and cognitive processes (e.g., derogation of alternatives; Simpson, Gangestad, \& Lerma, 1990) that help override inclinations towards an attractive alternative's immediate, but less meaningful rewards (e.g., physical attractiveness) in favor of the long-term value conferred by the present committed relationship. Yet, relative to those processes helping to maintain a relationship in the face of an attractive alternative, the cognitiveaffective mechanisms that facilitate a decision to leave one's partner are not well understood.

One candidate mechanism is the cognitive-affective experience of regret. Similar to the $\mathrm{CL}_{\text {alt }}$, regret involves the evaluation of differences between chosen outcomes and those produced by alternatives (Bell, 1982). However, contemporary theories of regret extend beyond a comparative judgment to include additional cognitive and emotional mechanisms that tie the process of comparison to subsequent decision making (Gilovich \& Medvec, 1995). For example, regret involves upward counterfactual thinking, the mental negation of prior behavior and the imagined improvement in outcomes pursuant to possible alternative actions. Also, according to Boninger, Gleicher, and Strathman (1994), these thoughts provide the cognitive basis for the "additional, poignant kind of unhappiness associated with knowing that the negative outcome could have been avoided" (p. 297) if a different decision were made.

The negative affective component of regret may connect unfavorable appraisals of one's actual choice (relative to alternatives) with particular corrective actions in the future (e.g., product switching; Inman, Dyer, \& Jia, 1997). In other words, the experience of regret may supply the motivational fuel for corrective behaviors. This idea is consistent with the more general notion that affective experiences influence judgment and play important roles in real-life decision making (see Peters, Västfjäll, Gärling, \& Slovic, 2006). With respect to judgments and decisions about intimate partnerships, regret may ensue from an unfavorable comparison between one's current choice and alternative options, thereby supplying the impetus for corrective action. More specifically, partner regret may link the presence of a higher quality alternative with the intention to partner switch. Thus, opponent to those processes that help maintain commitment, partner regret may be the operative cognitive-affective mechanism that facilitates partner switching when an individual believes that an attractive alternative will confer greater long-term dividends.

Importantly, however, the presence of a better alternative option is not necessary for experiencing regret when individuals are dissatisfied. In general, poor outcomes relative to expectations - the conditions for dissatisfaction - spontaneously produce the upward counterfactual thoughts underlying regret even in the absence of current alternatives (Markman, Gavanski, Sherman, \& McMullen, 1993). As such, individuals dissatisfied with their relationship may experience regret because their current partner is either compared to a foregone alternative (e.g., "If I had only dated Sue instead of Sally") or appears less favorable than being alone (e.g., "Had I only not dated Sue"). In either case, individuals in dissatisfying relationships may endorse regrets about their partnership, which may in turn generate prescriptions for future decision making regardless of whether an alternative option is currently available. In contrast, outcomes that exceed expectations do not lead to spontaneous upward counterfactuals (e.g., Sanna \& Turley, 1996), as satisfied individuals are potentially unmotivated to imagine scenarios that could undermine their present contentment. However, if a more attractive alternative is made salient, regrets may ensue and even a satisfied individual may intend to switch partners (also see, Tsiros \& Mittal, 2000).

\section{An Integrative Model of Partner Regret in Relationship Decision Making}

The proposed model contends that partner regret precedes behavioral intentions to partner switch, but may variably result from the unfavorable comparison of one's current partner to either an internal standard (i.e., the CL) or an external comparator (i.e., the $\mathrm{CL}_{\mathrm{alt}}$ ). When outcomes fall below expectations (i.e., the CL), dissatisfaction results and individuals need no external comparison point (i.e., an actual alternative) to experience partner regret. That is, partner regret may emerge as individuals fantasize about an actual, forgone, or imagined attracttive alternative. Likewise, they may envision the relative benefits of being single. By contrast, when individuals are satisfied (i.e., outcomes fall above the CL); the only potential generator of partner regret is a better alternative. It follows that only for those currently satisfied with their relationship will the presence of an attractive alternative be uniquely predictive of stay-leave decisions. Furthermore, only those without better options and who are relatively satisfied with their relationship will endorse few partner regrets and, thus, express little desire to exit their current relationship. Taken together, if partner regret motivates intentions to partner switch, then partner regret should mediate the association between a) an attractive alternative and intentions to partner switch under conditions of high satisfaction and b) the association between low relationship satisfaction and intentions to partner switch in the absence of attractive alternatives. 


\section{The Current Study}

Although theory and research implicate attractive alternatives as a predictor of relationship instability, few mediating mechanisms have been explored. The present goal was to examine the role of partner regret as a potential mediator within the broader social exchange framework for intimate partner decision-making. The potential contribution of partner regret to models of relationship decision making lies in a) specifying the affective link between evaluative judgments about the relationship and behavioral intentions to exchange partners and b) identifying some of the conditions under and mechanisms by which attractive alternatives and relationship dissatisfaction are more or less relevant to stay-leave decisions.

Two overarching hypotheses were tested. First, it was hypothesized that partner regret would mediate the association between having an attractive alternative and a greater intent to partner switch, but only for those relatively satisfied with their current relationship. This is because partner regret in less satisfying relationship is likely even without an external comparator, whereas more satisfied individuals would only experience partner regret in light of a more attractive option. Second, it was predicted that high versus low relationship satisfaction would only differentiate individuals in terms of partner regret for those without an attractive alternative. Specifically, it was hypothesized that increased partner regret would mediate the association between low relationship satisfaction and greater hypothetical intentions to partner switch, but only for those currently without a better available alternative. This is because individuals without an attractive alternative will base the evaluation of their relationship outcomes against an internal standard (i.e., the CL), and only those with outcomes falling below expectations will experience partner regret.

Given that regret is most likely to influence behavior when potential alternatives are many and corrective action is still possible, the population of university students in premarital and dating relationships was sampled. These individuals are exposed to numerous alternatives and likely have few barriers to relationship dissolution. Furthermore, the university setting is perhaps the quintessential marriage marketplace, wherein individuals continually evaluate and compare potential mates within their current geographic proximity (Fossett \& Kiecolt, 1991) at a time when the formation of intimate relationships is a primary developmental task (Furman \& Shaffer, 2003).

In addition, for a more rigorous test of our hypotheses, several additional variables were statistically controlled; such as dispositional tendencies to regret life decisions, as well as several individual and relationship factors representing potential third variables (e.g., relationship length). Also statistically controlled was the amount of resources invested in the relationship_-both tangible (e.g., shared finances) and abstract (e.g., time and effort) - that would be lost or diminished should the relationship dissolve. Likewise, commitment level-the subjective experience of connectedness to one's partner-was also accounted for in the model. Both investment and commitment are uniquely associated with an individual's decision to stay or leave a relationship and can mitigate the influence of an attractive alternative on relationship instability (Le \& Agnew, 2003). It was therefore important to provide some evidence that the proposed effects are robust across individuals differing in their level of commitment to and investment in their romantic relationship.

\section{Method}

\section{Participants and Procedures}

Ninety-four undergraduate participants (12 males and $82 \mathrm{fe}-$ males) from a Southeastern University participated in the study. Participants were recruited through flyers placed on campus, announcements made in undergraduate classes, and through the Psychology Department's online recruitment system. Participants were required to be 19 years old or older and in a monogamous heterosexual relationship. Those that met these criteria were invited to the lab and ran individually. Each completed several computer-administered questionnaires and cognitive tasks assessing relationship-relevant variables (some unrelated to the current analyses) that were set up in advance by a research assistant. Administration of the questionnaires was counterbalanced and took approximately 45 minutes to complete. Participants chose either extra credit or $\$ 10$ for compensation.

The sample comprised individuals in casual dating relationships $(n=7)$, serious dating relationships $(n=82)$, or who were engaged to be married $(n=5)$; with the average relationship length, in months, being 4.1 ( $\mathrm{SD}=2.9), 22.3(\mathrm{SD}=17.6)$, and $24.8(\mathrm{SD}=11.4)$, respectively. Participants' mean age was 20.3 $(\mathrm{SD}=1.0)$, with the majority of the sample identifying as Caucasian $(89.2 \%)$. The remaining participants identified as African American (7.5\%), Native American (1.1\%), Latino-Hispanic $(1.1)$, or Other $(1.1 \%)$. Approximately $2 \%$ of the sample lived together; $51 \%$ lived separately but spent nights together: rarely $(21 \%)$, frequently (13\%), or almost always (17\%); $15 \%$ lived separately and did not spend nights together; and $32 \%$ were in long-distance relationships.

\section{Measures}

\section{Dispositional Regret}

The 5-item Regret Scale developed by Schwartz et al. (2002) was used to measure an individual's dispositional tendency to experience regret (e.g., When I think about how I'm doing in life, I often assess opportunities I have passed up). Participants respond to each item using a 7-point Likert-type scale ranging from 0 (completely disagree) to 6 (completely agree) with possible scores ranging from 0 to 30 . The observed range was 0 to $25(\mathrm{M}=18.8, \mathrm{SD}=4.8) ; \alpha=0.75$.

\section{Partner Regret}

The Partner Regret Scale (PRS) was developed for this study by adapting items from Schwartz et al.'s (2002) measure to assess regret specific to partner selection (see the Appendix) using the same 7-point scale. This approach afforded two notable advantages. First, it helped equate the measures of dispositional and partner-specific regret on extraneous psychometric characteristics: This helps prevent differences in measurement from confounding the interpretation of any significant effects. Second, the items from Schwartz et al.'s measure capture different facets of regret's operational domain. For example, some items tap retrospective or contemporaneous regrets driven by commission (e.g., "I sometimes feel like I chose the wrong person when I find out about... a previous or potential relationship partner..."), whereas others focus more so on omission-based regret (e.g., “... I often assess opportunities I have passed up.”). Nevertheless, a principal components analysis showed that the PRS items loaded onto a single construct accounting for $69 \%$ of the response variability (loadings ranged from 0.75 to 0.87 ). 
Taken together, items on the PRS cover a range of content from the one-dimensional construct of partner regret. Total scores ranged from 0 to $27(\mathrm{M}=12.9, \mathrm{SD}=7.1) ; \alpha=0.89$.

\section{Attractive Alternatives}

The measure of attractive alternatives was based on Miller's (1997) definition of realistic alternatives, the number of "people who you might be interested in dating and who might be interested in dating you" (p. 760). However, this operation was extended by asking participants, "... of these, for how many would you consider leaving your current partner". This latter question was most appropriate for testing the proposed model, which was that partner regret ensues when the value of the $\mathrm{CL}_{\text {alt }}$ for the alternative exceeds the reward value associated with one's current partner. Approximately one quarter of the sample endorsed having at least one alternative that is more attractive than their current partner; only two individuals endorsed more than one and so this variable was dichotomized to simplify interpretation of the results.

\section{Relationship Satisfaction}

The 4-item Couple Satisfaction Index (CSI4: Funk \& Rogge, 2007) was used to measure relationship satisfaction. Item stems directly tap the relative favorability of an individual's subjecttive evaluative judgment of his or her relationship (e.g., Please indicate the degree of happiness, all things considered, of your relationship). Summed scores can range from 0 to 28 , with higher scores being indicative of greater satisfaction. The CSI4 scores presently ranged from 5 to $28(\mathrm{M}=22.3, \mathrm{SD}=5.1) ; \alpha=0.96$.

\section{Relationship Investment and Commitment}

The Investment and Commitment subscales of the Investment Model Scale (IMS; Rusbult, Martz, \& Agnew, 1998) were also administered. The 5-item Investment subscale contains items that assess the resources attached to the relationship that would be lost or diminished should the relationship terminate [e.g., Many aspects of my life have become linked to my partner (recreational activities, etc.)]. The Commitment subscale contains 7 items that assess one's subjective orientation towards the relationship (e.g., "I feel very attached to our relationship, very strongly linked to my partner") and its maintenance (e.g., "I am committed to maintaining my relationship with my partner"). Items on both subscales are rated on a 5-point Likert continuum with qualitative anchors of 1 (Don't Agree at All) and 5 (Agree Completely). Current scores on the Investment scale ranged from 6 to $25(\mathrm{M}=17.5, \mathrm{SD}=4.4), \alpha=0.78$; and, on the Commitment scale, from 7 to $35(\mathrm{M}=28.6, \mathrm{SD}=7.1), \alpha$ $=0.93$.

\section{Hypothetical Likelihood of Partner Switching}

The criterion was phrased as a hypothetical to create variability in behavioral intentions for individuals without current alternatives: "Hypothetically, if someone significantly better than your current partner was interested in you, what is the probability that you would end your current relationship". Participants rated this question on a probability scale ranging from $0 \%$ to $100 \%: \mathrm{M}=27.7 \%, \mathrm{SD}=29.6$.

\section{Planned Analyses}

Study hypotheses were tested using a moderated-mediation analysis that was executed with the MODMED SPSS macro developed by Preacher, Rucker, and Hayes (2007). This approach tests moderated-mediation effects across two OLS regression models. The first model estimates the hypothesized moderation effects, which in this case pertain to the interaction between relationship satisfaction (low versus high) and attracttive alternatives (present $=1$; absent $=0$ ) on partner regret. It was predicted that a) relatively satisfied individuals with an alternative would experience greater partner regret than comparably satisfied individuals without an alternative; and b) relatively dissatisfied individuals without a more attractive alternative will experience more partner regret than more satisfied individuals who are also without alternatives.

The second model, which builds off the first, regresses hypothetical intentions to partner switch on relationship satisfaction, attractive alternatives, and their interaction; as well as partner regret (the proposed mediator). The obtained regression weights are then used to examine whether the proposed mediation effects vary across levels of a given moderator (i.e., attracttive alternatives or relationship satisfaction). Currently tested was whether a) the effect of an attractive alternative on hypothetical intentions to partner switch by way of increased partner regret (mediation) occurred only for individuals endorsing higher relationship satisfaction (moderated-mediation 1); and b) the indirect effect of relationship satisfaction on intentions to partner switch through partner regret (mediation) occurred only when no alternatives were present (moderated-mediation 2). Mediation effects were calculated using the Sobel method and a bootstrapping approach (1000 samples) was employed to obtain less biased parameter estimates.

\section{Results}

\section{Data Preparation}

Statistically controlled in the model were relationship length and status, participant's and partner's age, gender, cohabitation status, and whether or not the relationship was long-distance. Cohabitating and long-distance relationships were coded as 1 (otherwise 0). Relationship status was constructed as an ordinal variable, with higher values representing a greater degree of commitment (engaged $=2$ ) than lower values (casual dating = 0 ). All the continuous variables were normally distributed (or transformation did not alter the pattern of results). Continuous predictors were standardized to facilitate interpretation. There were no univariate or multivariate outliers and the assumptions of OLS regression were met.

\section{Preliminary Analyses}

Confirmatory factor analyses were run to ensure the appropriateness of the proposed measurement model. Specifically, the model a) regressed items from the PRS and CSI onto separate, but oblique (i.e., correlated) latent variables representing partner regret and satisfaction, respectively; and b) included attractive alternatives and intentions to partner switch as separate single-indicator variables that were allowed to intercorrelate with each other and with both latent factors. In effect, this model tests whether the constructs of primary interest - and the observables chosen to measure them-actually represented correlated, but ultimately distinct phenomena. This model was a good fit to the data (see Table 1). Two additional models were run to provide a comparison. The first specified all of the observed variables onto a single latent construct, which provided a 
Table 1.

Confirmatory factor analytic fit indices for the hypothesized and comparison measurement models.

\begin{tabular}{lccccc}
\hline \multicolumn{7}{c}{ Fit Indices } \\
\hline Model & $x^{2}(d f)$ & $x^{2} / d f$ & CFI & RMSEA & SRMR \\
\hline Hypothesized Model & $41.83(37)$ & 1.13 & 0.93 & 0.04 & 0.069 \\
Comparison Model 1 & $157.41(43)^{* *}$ & 3.68 & 0.87 & 0.17 & 0.09 \\
Comparison Model 2 & $151.35(43)^{* *}$ & 3.53 & 0.88 & 0.17 & 0.09 \\
\hline
\end{tabular}

Note: $\mathrm{N}=94 . \mathrm{CFI}=$ Comparative Fit Index; RMSEA = Root Mean Square Error of Approximation; SRMR = Standardized Root Mean Square Residual. Although the criteria for acceptable fit somewhat vary; CFI values above 0.90 generally represent good fitting models; as do RMSEA and SRMR values under 0.07 and $x^{2} / d f$ less than 2 . Statistically significant $x^{2}$ values indicate a poor fitting model; ${ }^{* *}<0.01$.

poor fit. The second model specified the CSI and PRS items as a single latent variable, but attractive alternatives and intentions to partner switch were included as separate single-indicator variables (all of which were allowed to intercorrelate). This model was also a poor fit to the observed data, and the use of appropriate modification indices did not substantially improve model fit in either case. Taken together, these findings suggest that the current measures of partner regret, relationship satisfaction, attractive alternatives, and hypothetical intentions to partner switch represent separate underlying constructs.

\section{Moderated Mediation Analysis}

The simple and interaction effects of attractive alternatives and relationship satisfaction on partner regret were estimated first. The simple effect for attractive alternatives and relationship satisfaction were both significant, as was their interaction (see Table 2). As predicted, individuals high in satisfaction, but without attractive alternatives, experienced significantly less partner regret than their counterparts with attractive alternatives. Also, individuals without attractive alternatives demonstrated higher levels of partner regret when relationship satisfaction was low versus high (see Figure 1).

To obtain the regression weights for the mediation tests, hypothetical intentions to partner switch were regressed onto partner regret, relationship satisfaction, attractive alternatives, the interaction term, and the control predictors. (The results are displayed in Table 2). It was then examined if the effect of attractive alternatives on hypothetical intentions to partner switch was mediated by partner regret, with this indirect effect being conditional on higher levels of relationship satisfaction (moderated-mediation 1). The results supported the hypothesis: Partner regret mediated the influence of attractive alternatives, with the effects of the former on the likelihood of partner switching being statistically significant for more highly satisfied participants (+1SD), $\beta=17.15(S E=8.10), p<0.05$, but not for those comparatively less satisfied ( $-1 \mathrm{SD}), \beta=4.97$ ( $S E=3.54)$, ns.

It was then examined whether or not relationship (dis)satisfaction predicted hypothetical intentions by way of partner regret when no better alternatives were available (moderatedmediation 2). These findings supported the hypothesis.

Specifically, lower relationship satisfaction predicted higher partner regret and, subsequently, greater hypothetical probabilities of partner switching when attractive alternatives were absent, $\beta=-10.14(S E=4.17), p<0.05$. Partner regret did not

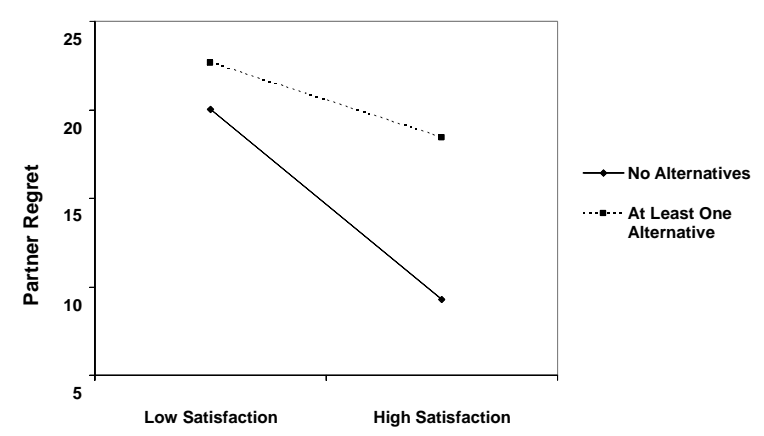

Figure 1.

Interaction effect for relationship satisfaction and attractive alternatives in predicting partner regret.

significantly mediate the association between relationship satisfaction and outcomes when alternatives were present; $\beta=$ $-3.75(S E=2.57)$, ns. In other words, higher partner regret linked the association between lower relationship satisfaction and greater hypothetical intentions to partner switch only for individuals currently without a better alternative.

\section{Discussion}

The results highlight that partner regrets emerge either when individuals are unsatisfied with their relationship or when relatively satisfied individuals have a better alternative. Although some unsatisfied individuals also had better alternatives, their levels of partner regret were fairly indistinguishable from their unsatisfied but option-less counterparts. As theorized, this is perhaps because less satisfied individuals have a number of different reference points that could elicit the upward counterfactuals underlying partner regret, such as foregone alternatives or unmet expectations. In other words, presently having a better alternative may be nonessential for experiencing partner regret as relationship satisfaction declines. By comparison, more satisfied individuals may be disinclined to view their partner less favorably than forgone alternatives or being alone. Thus, only a presently better alternative serves as a relevant comparison point. As such, only individuals who were relatively satisfied and without a more attractive alternative experienced little in the way of partner regret and, thus, had little intention to partner switch in the future.

In one sense, partner regret may ultimately serve the same function as a commitment device: To maximize the individual's long-term relationship outcomes. However, commitment devices accomplish this by preventing the exchange of larger delayed relationship benefits for shorter-term rewards, whereas partner regret fosters better long-term outcomes by facilitating a current switch to a more suitable alternative. This notion may provide an adjunctive explanation for the modest correlation between relationship satisfaction and whether a relationship dissolves (see Karney \& Bradbury, 1995). An existing account is that barriers to relationship dissolution prevent some dissatisfied individuals from otherwise leaving their partnerships, thus creating statistical noise at the distressed end of the continuum (Previti \& Amato, 2003). However, attenuation may also occur because some highly satisfied individuals abandon their relationships in the presence of relatively more attractive alternatives when motivated by partner regret.

Facilitating a switch to a more suitable alternative may be 
Table 2.

OLS regression findings for the moderation and mediation models.

\begin{tabular}{|c|c|c|c|c|c|c|}
\hline \multirow[b]{3}{*}{ Predictor Variables } & \multicolumn{3}{|c|}{ Moderator Model } & \multicolumn{3}{|c|}{ Mediator Model } \\
\hline & \multicolumn{3}{|c|}{ Criterion: PRS } & \multicolumn{3}{|c|}{ Criterion: Probability of Partner Switching } \\
\hline & $\beta(S E)$ & $t$ & $s r^{2}$ & $\beta(S E)$ & $t$ & $s r^{2}$ \\
\hline PRS & - & - & - & $13.50(4.56)$ & $2.96^{* * *}$ & 0.23 \\
\hline Alternatives & $5.88(1.43)$ & $4.12^{* *}$ & 0.24 & $11.56(9.05)$ & 1.28 & 0.10 \\
\hline CSI4 & $-5.36(0.57)$ & $-9.34^{* *}$ & -0.54 & $-3.43(4.78)$ & -0.72 & -0.06 \\
\hline CSI4 $\times$ Alternatives & $3.26(1.12)$ & $2.91^{* *}$ & 0.17 & $-2.28(6.79)$ & -0.34 & -0.03 \\
\hline Control Variables & $\beta(S E)$ & $t$ & $s r^{2}$ & $\beta(S E)$ & $t$ & $s r^{2}$ \\
\hline Gender & $-2.00(1.28)$ & -1.56 & -0.09 & $0.65(7.48)$ & 0.09 & 0.01 \\
\hline Age & $0.19(0.51)$ & -0.38 & 0.02 & $-0.48(2.95)$ & -0.16 & -0.01 \\
\hline Partner Age & $-0.16(0.54)$ & -0.29 & -0.02 & $-0.62(3.09)$ & -0.20 & -0.02 \\
\hline Dispositional Regret & $2.02(0.46)$ & $4.43^{* *}$ & 0.25 & $-1.26(2.94)$ & -0.43 & -0.03 \\
\hline Relationship Status & $-0.84(1.26)$ & 0.67 & -0.04 & $-0.87(7.25)$ & -0.12 & -0.01 \\
\hline Relationship Length & $0.62(0.44)$ & 1.40 & 0.08 & $-5.61(2.58)$ & $-2.17^{* *}$ & -0.17 \\
\hline Long Distance & $-0.35(0.97)$ & -0.36 & -0.02 & $3.10(5.59)$ & 0.55 & 0.04 \\
\hline Cohabitation & $0.99(1.20)$ & 0.82 & 0.05 & $4.93(6.95)$ & 0.71 & 0.06 \\
\hline IMS-Investment & $0.29(0.59)$ & 0.49 & 0.03 & $3.54(3.37)$ & 1.05 & 0.08 \\
\hline IMS-Commitment & $0.48(0.56)$ & 0.86 & 0.05 & $-5.77(3.23)$ & -1.79 & -0.14 \\
\hline
\end{tabular}

Note: $\mathrm{N}=94$. All continuous predictor and control variables were standardized so regression weights represent the expected increase in the criterion per a one standard deviation increase (from the mean) in a predictor. CSI4 $=4$-item Couples Satisfaction Index; IMS $=$ Investment Model Scale; and PRS $=$ Partner Regret Scale. $s r^{2}=$ squared semipartial correlation; ${ }^{*} p<0.05 ;{ }^{* *} p<0.01$ (two-tailed).

only one way in which partner regret can lead to better long-term relationship outcomes. For example, even when no better alternative is currently present, partner regret may be useful in averting increased investment in and commitment to unsatisfying relationships. Research by $\mathrm{Ku}(2008)$ showed that negative outcomes following increased commitment to financial decisions elicited post-choice regret; which, in turn, led to a deescalation of commitment. When applied to the context of intimate relationships, these findings suggest that the experience of partner regret may help prevent unsatisfied individuals from throwing good love after bad.

Notably, neither relationship satisfaction nor attractive alternatives significantly predicted intentions to partner switch when controlling for partner regret; evoking Baron and Kenny's (1986) concept of complete mediation. Although relationship satisfaction and attractive alternatives involve different reference points (i.e., the $\mathrm{CL}$ and $\mathrm{CL}_{\text {alt }}$, respectively), the present findings suggest that partner regret may be the affective intermediary that links both types of comparative judgments to intimate partner decision-making. Moreover, partner regret significantly predicted hypothetical stay-leave intentions when controlling for these and other relevant constructs (e.g., relationship investment). One explanation is that the unique effects of partner regret stemmed from the way in which attractive alternatives were measured. Specifically, we did not assess how much more attractive were the alternatives. Possibly, as the relative quality of a more attractive alternative increased; so too did the amount of regret an individual experienced over their current partner selection. Only controlled for was the presence versus absence of an alternative (and not degree of relative quality); so there possibly remained criterion-relevant variabi- lity in the measure of partner regret for those with more attracttive alternatives. It is also possible, however, that there are some unique properties of partner regret that are not reducible to either of its hypothesized precursors (i.e., being unsatisfied or having better options).

\section{Strengths and Limitations}

Although many of the constructs under investigation were similar in nature, it is unlikely that the present findings were an artifact of any overlap in their formulation or assessment. Indeed, any degree of overlap would have increased Type II error. Specifically, shared explanatory variance is omitted from the regression weights; reducing the amount of criterion-relevant variance left in the individual predictors. This would make their hypothesized unique effects more difficult to detect and, thus, cannot serve as an alternative interpretation for their significant associations with the criteria. Furthermore, the proposed measurement model was validated using a confirmatory approach, thus providing empirical support for the distinction between the variables and their respective indicators. Taken together, the careful approach to measurement enhanced internal validity and is therefore a point of strength to the current study.

Nevertheless, inferring causality is still difficult because the hypothesized effects were necessarily constrained by a correlational design. Ultimately, some degree of internal validity must be conceded because the presence or absence of a more attractive alternative cannot be randomly assigned (for somewhat obvious reasons). Even if this were possible, doing so would effectively bolster internal validity at the expense of external validity (as random assignment of alternative partners is 
unlikely in any naturalistic setting). However, attempts were made to strengthen the internal validity of the present design in two primary ways. The first is that extraneous factors that could otherwise provide alternative accounts for the findings were statistically controlled. That all potentially relevant variables were included in the model is, of course, uncertain. However, the findings were indeed robust when accounting for the most apparently relevant third variables (e.g., relationship length, investment, etc.).

The other way in which inferential power was bolstered was in specifying, a priori, a network of particular effects derived from an explicit theoretical model. According to Cochran (1965), that the hypothesized pattern emerged as predicted not only supports the proposed model; but also makes it more difficult to generate alternative models that are a) as parsimonious and b) also account for the overall pattern of demonstrated effects in their entirety (for similar arguments, see Cohen, Cohen, West, \& Aiken, 2003). Nevertheless, any set of findings must always be considered alongside the more general problem with induction: You can never be completely sure there isn't some model better than your own for what was observed.

Other aspects of this study also warrant further consideration. First, the probability of switching to a more attractive partner was measured as a hypothetical. This approach was used because a) the hypotheses compared stay-leave decision making in those with and without an actual alternative presently available; and b) garnering enough option-less individuals who ultimately encountered a better alternative would require a rather extended longitudinal design to ensure adequate statistical power (which seemed premature for such an exploratory endeavor). Also, the use of hypothetical decisional intentions as outcomes is a fairly common design in regret research (e.g., Inman \& Zeelenberg, 2002), and there is an established link between anticipatory regret and future behavior (see Zeelenberg, 1999). Nevertheless, whether or not hypothetical probabilities correspond to stay-leave decisions in intimate relationships requires further investigation.

Second, the sample comprised dating and premarital relationships; which, although appropriate to the research question, leaves open the possibility that the present effects are largely contingent upon the absence of significant barriers that would preclude separation in other dyads (e.g., children). Despite evidence that individuals remain open to alternative relationships even while married (South, Trent, \& Shen, 2001), and given that relationship type, investments, and subjective commitment level were statistically accounted for; subsequent research should further examine if certain specific barriers to dissolution represent significant boundary conditions to the presently observed effects.

Third, it is hard to determine whether participants without better alternatives were technically dissatisfied when partner regrets began to develop, or just less satisfied relative to others in the sample. This latter possibility seems more likely given the relatively high average level of relationship satisfaction endorsed by participants, which is not entirely surprising in hindsight. Indeed, it is likely that college relationships are relatively absent of the costs that potentially emerge as commitment level increases (e.g., conflict over shared finances); as well as have fewer barriers to dissolution and more frequent contact with potential suitors. As such, the population overall may contain few individuals that are entirely dissatisfied (i.e., high costs and low rewards) that have not already terminated their relationship or exchanged partners. As such, participants at the lower end of the current distribution may be better characterized as relatively unsatisfied (i.e., low costs and low rewards). Nevertheless, these individuals reported partner regret even though they may not have been entirely dissatisfied with their relationship. As such, the observed effects still give support to the proposed model, but may further suggest that the upward counterfactuals eliciting partner regret emerge more gradually as relationship outcomes trend towards minimal expectations.

Last, the implications for the present study are constrained by the homogeneity of the sample. Most notable is the disproportionate amount of women in the sample, with the number of men perhaps being insufficient to adequately control for gender effects. Although Le and Agnew's (2003) meta-analysis showed no relevant gender differences in the directional or zero-order associations between variables in the social exchange model (e.g., attractive alternatives); there is some evidence for gender differences in retrospective regrets about past intimate relationships (Roese et al., 2006). Specifically, men more frequently regret inaction (i.e., missed opportunities), whereas women equally regret errors of commission and omission. However, the present study focused on regrets pertaining to current, as opposed to forgone alternatives; and the measure of partner regret potentially captured both types of decisional errors. Taken together, potential gender differences in regret may not have substantially altered the present findings overall. Moreover, the inability to fully generalize the effects to all populations and settings does not undermine their internal validity, and the current findings at least establish preliminary evidence for the hypothesized role of partner regret in stay-leave decisions.

\section{Future Directions}

The ultimate aim of the present study was to provide an initial bridge between the literatures on regret and relationship decision making. In doing so, the current findings highlight the need and provide the foundation for additional study in this area. For example, this study focused solely on stay-leave decisions, whereas Zeelenberg and Pieters (2007) suggest a number of other possible sequelae of regret; such as delaying or avoiding a decision or ensuring its reversibility. Likewise, there is considerable evidence that the experience of regret, its anticipation, and influence on decision making hinges on several situational factors; such as when post-choice knowledge (versus ignorance) about the outcomes of a foregone alternative is expected (Ritov \& Baron, 1995). Determining whether and how such findings on regret translate into the context of intimate partner decision making will likely be of interest to researchers across disciplines.

There are also many avenues of research that could expand theoretical models of intimate partner decision making. For instance, the current findings imply that research on counterfactual thinking may interface with social exchange constructs. The nature of specific upward and downward relationship counterfactuals, as well as their influence on stay-leave decisions, may prove to be an exciting area for additional study. As an example, favorable evaluations of one's current partner relative to potential or foregone alternatives (i.e., downward counterfactuals) may elicit feelings of relief, which could foster increased investment or commitment (Arriaga, personal com- 
munique; also see Connolly \& Butler, 2006). Another possibility is to include other affective mechanisms in the social exchange model, which tends to focus more so on the cognitive aspects of stay-leave decisions. Indeed, there is already experimental and consumer research indicating that other of its central constructs, such as satisfaction, have an affective basis (e.g., disappointment; Zeelenberg et al., 1998). Moreover, these affective substrates may interact in theoretically meaningful ways. For example, the experience of partner regret may be necessary to instigate corrective action by overriding the experienced loss tied to investments sunk in one's current relationship. In any case, these possible avenues for further investigation highlight that the current findings not only connect intimate partner decision making with research on regret, but also with varied literatures relevant to judgment and decision making (e.g., economics, cognitive psychology, etc.). Extending to intimate relationships the theoretical and empirical advances contained therein (e.g., Decision Affect Theory; Mellers, Schwartz, Ho, \& Ritov, 1997) will likely broaden the conceptual horizon currently on offer from social exchange theory and its derivatives (e.g., the Investment Model; Rusbult et al., 1998).

\section{Conclusion}

The dissolution of seemingly happy relationships might be a byproduct of an unfavorable evaluation of one's partner as compared to alternatives, which increases the probability of partner switching by eliciting partner regret. Moreover, the presence of an attractive alternative may be unnecessary to generate partner regret in less satisfied individuals, ostensibly providing the link between conditions of lower satisfaction and an increased likelihood of partner switching (should a better alternative later emerge). Taken together, high relationship satisfaction does not completely buffer against salient alternatives, whereas their presence may not uniquely impinge on relationship longevity when satisfaction is low and partner regrets are multiply determined. These findings highlight a place for partner regret in social exchange models of intimate partner decision making, building an initial bridge between their respective literatures.

\section{Acknowledgements}

We would like to thank Kristopher J. Preacher for reviewing this manuscript and providing feedback on our statistical analyses.

\section{REFERENCES}

Baron, R. M., \& Kenny, D. A. (1986). The moderator-mediator variable distinction in social psychological research: Conceptual, strategic and statistical considerations. Journal of Personality and Social Psychology, 51, 1173-1182. doi:10.1037/0022-3514.51.6.1173

Bell, D. E. (1982). Regret in decision making under uncertainty. Operations Research, 30, 931-981. doi:10.1287/opre.30.5.961

Boninger, D. S., Gleicher, F., \& Strathman, A. (1994). Counterfactual thinking: From what might have been to what might be. Journal of Personality and Social Psychology, 67, 297-307. doi:10.1037/0022-3514.67.2.297

Brehaut, J. C., O'Connor, A. M., Wood, T. J., Hack, T. F., Siminoff, L., Gordon, E., \& Feldman-Stewart, D. (2003). Validation of a decision regret scale. Medical Decision Making, 23, 281-292. doi:10.1177/0272989X03256005

Cochran, W. G. (1965). The planning of observational studies of human populations (with discussion). Journal of the Royal Statistical Society, Series A, 128, 134-155.

Cohen, J., Cohen, P., West, S. G., \& Aiken, L. S. (2003). Applied multiple regression/correlation analysis for the behavioral sciences (3rd ed.). Mahwah, NJ: Lawrence Erlbaum Associates.

Connolly, T., \& Butler, D. (2006). Regret in economic psychological theories of choices. Journal of Behavioral Decision Making, 19, 139-154. doi: $10.1002 / \mathrm{bdm} .510$

De Bondt, W. F. M., \& Thaler, R. H. (1994). Financial decision-making in markets and firms: A behavioral perspective. Cambridge, MA: National Bureau of Economic Research, Inc.

Fletcher, G. J. O., Simpson, J. A., Thomas, G., \& Giles, L. (1999). Ideals in intimate relationships. Journal of Personality and Social Psychology, 76, 72-89. doi:10.1037/0022-3514.76.1.72

Fossett, M. A., \& Kiecolt, K. J. (1991). A methodological review of the sex ratio: Alternatives for comparative research. Journal of Marriage and Family, 53, 941-957. doi:10.2307/352999

Funk, J. L., \& Rogge, R. D. (2007). Testing the ruler with item response theory: Increasing precision of measurement for relationship satisfaction with the couples satisfaction index. Journal of Family Psychology, 21, 572-583. doi:10.1037/0893-3200.21.4.572

Furman, W., \& Shaffer, L. (2003). The role of romantic relationships in adolescent development. In P. Florsheim (Ed.), Adolescent romantic relations and sexual behavior: Theory, research, and practical implications (pp. 3-22). Mahwah, NJ: Lawrence Erlbaum Associates Publishers.

Gilovich, T., \& Medvec, V. H. (1995). The experience of regret: What, when, and why. Psychological Review, 102, 379-395. doi:10.1037/0033-295X.102.2.379

Gonzaga, G. C., Haselton, M. G., Smurda, J., Davies, M., \& Poore, J. C. (2008). Love, desire, and the suppression of thoughts of romantic alternatives. Evolution and Human Behavior, 29, 119-126. doi:10.1016/j.evolhumbehav.2007.11.003

Inman, J., Dyer, J. S., \& Jia, J. (1997). A generalized utility model of disappointment and regret effects on post-choice valuation. Marketing Science, 16, 97-111. doi:10.1287/mksc.16.2.97

Inman, J., \& Zeelenberg, M. (2002). Regret in repeat purchase versus switching decisions: The attenuating role of decision justifiability. Journal of Consumer Research, 29, 116-128. doi:10.1086/339925

Karney, B. R., \& Bradbury, T. N. (1995). The longitudinal course of marital quality and stability: A review of theory, methods, and research. Psychological Bulletin, 118, 3-34. doi: $10.1037 / 0033-2909.118 .1 .3$

$\mathrm{Ku}, \mathrm{G}$. (2008). Learning to de-escalate: The effects of regret in escalation of commitment. Organizational Behavior and Human Decision Making Processes, 105, 221-232. doi:10.1016/j.obhdp.2007.08.002

Le, B., \& Agnew, C. R. (2003). Commitment and its theorized determinants: A meta-analysis of the investment model. Personal Relationships, 10, 37-57. doi:10.1111/1475-6811.00035

Levinger, G. (1965). Marital cohesiveness and dissolution: An integrative review. Journal of Marriage and the Family, 27, 19-28. doi: $10.2307 / 349801$

Maner, J. K., Rouby, D. A., \& Gonzaga, G. C. (2008). Automatic inattention to attractive alternatives: The evolved psychology of relationship maintenance. Evolution and Human Behavior, 29, 343-349. doi:10.1016/j.evolhumbehav.2008.04.003

Markman, K. D., Gavanski, I., Sherman, S. J., \& McMullen, M. N. (1993). The mental simulation of better and worse possible worlds. Journal of Experimental Social Psychology, 29, 87-109. doi:10.1006/jesp.1993.1005

McNulty, J. K., \& Karney, B. R. (2002). Expectancy confirmation in appraisals of marital interactions. Personality and Social Psychology Bulletin, 28, 764-775. doi:10.1177/0146167202289006

Mellers, B. A., Schwartz, A., Ho, K., \& Ritov, I. (1997). Decision affect theory: Emotional reactions to the outcomes of risky options. Psychological Science, 8, 423-429. doi:10.1111/j.1467-9280.1997.tb00455.x

Miller, R. S. (1997). Inattentive and contented: Relationship commitment and attention to alternatives. Journal of Personality and Social Psychology, 73, 758-766. doi:10.1037/0022-3514.73.4.758

Peters, E., Västfjäll, D., Gärling, T., \& Slovic, P. (2006). Affect and 
decision making: A "hot" topic. Journal of Behavioral Decision Making, 19, 79-85. doi:10.1002/bdm.528

Preacher, K. J., Rucker, D. D., \& Hayes, A. F. (2007). Addressing moderated mediation hypotheses: Theory, methods, and prescriptions. Multivariate Behavioral Research, 42, 185-227. doi: $10.1080 / 00273170701341316$

Previti, D., \& Amato, P. R. (2003). Why stay married? Rewards, barriers, and marital stability. Journal of Marriage and Family, 65, 561573. doi:10.1111/j.1741-3737.2003.00561.x

Ritov, I., \& Baron, J. (1995). Outcome knowledge, regret, and omission bias. Organizational Behavior and Human Decision Processes, 64, 119-127. doi:10.1006/obhd.1995.1094

Roese, N. J., Pennington, G., Coleman, J., Janicki, M., Li., N., \& Kenrick, D. T. (2006). Sex differences in regret: All for love or some for lust? Personality and Social Psychology Bulletin, 32, 770-780. doi:10.1177/0146167206286709

Roese, N. J., \& Summerville, A. (2005). What we regret most... and why. Personality and Social Psychology Bulletin, 31, 1273-1285. doi:10.1177/0146167205274693

Rusbult, C. E., Martz, J. M., \& Agnew, C. R. (1998). The Investment Model Scale: Measuring commitment level, satisfaction level, quality of alternatives, and investment size. Personal Relationships, 5, 357391. doi:10.1111/j.1475-6811.1998.tb00177.x

Sanna, L. J. and Turley, K. J. (1996). Antecedents to spontaneous counterfactual thinking: Effects of expectancy violation and outcome valence. Personality and Social Psychology Bulletin, 22, 906-919. doi:10.1177/0146167296229005

Schwartz, B., Ward, A., Monterosso, J., Lyubomirsky, S., White, K., \& Lehman, D. R. (2002). Maximizing versus satisficing: Happiness is a matter of choice. Journal of Personality and Social Psychology, 83, 1178-1197. doi:10.1037/0022-3514.83.5.1178

Simpson, J. A., Gangestad, S. W., \& Lerma, M. (1990). Perception of physical attractiveness: Mechanisms involved in the maintenance of

\section{Appendix}

Partner Regret Scale

1) I try to get information about how my life would be if I stayed with a previous partner, as opposed to the one I'm with.

2) I think I might have found a better relationship partner if I had kept looking instead of choosing to be with my current partner. romantic relationships. Journal of Personality and Social Psychology, 59, 1192-1201. doi:10.1037/0022-3514.59.6.1192

South, S. J., Trent, K., \& Shen, Y. (2001). Changing partners: Toward a macrostructural-opportunity theory of marital dissolution. Journal of Marriage and Family, 63, 743-754. doi:10.1111/j.1741-3737.2001.00743.x

Thibaut, J. W., \& Kelley, H. H. (1959). The social psychology of groups. Oxford: Wiley.

Tsiros, M., \& Mittal, V. (2000). Regret: A model of its antecedents and consequences in consumer decision making. Journal of Consumer Research, 26, 401-417. doi:10.1086/209571

Udry, J. (1981). Marital alternatives and marital disruption. Journal of Marriage and the Family, 43, 889-897. doi:10.2307/351345

Zeelenberg, M. (1999). Anticipated regret, expected feedback and behavioral decision making. Journal of Behavioral Decision Making, 12, $93-106$.

doi:10.1002/(SICI)1099-0771(199906)12:2<93::AID-BDM311>3.0. $\mathrm{CO} ; 2-\mathrm{S}$

Zeelenberg, M., \& Pieters, R. (2007). A theory of regret regulation 1.0. Journal of Consumer Psychology, 17, 3-18. doi:10.1207/s15327663jcp1701_3

Zeelenberg, M., \& Pieters, R. (2009). On the consequences of mentally simulating future foregone outcomes: A regret regulation perspective. In K. D. Markman, W. M. P. Klein, \& J. A. Suhr (Eds.), The handbook of imagination and mental simulation (pp. 417-428). New York: Psychology Press.

Zeelenberg, M., van Dijk, W. W., van der Pligt, J., Manstead, A. S. R., van Empelen, P., \& Reinderman, D. (1998). Emotional reactions to the outcomes of decisions: The role of counterfactual thought in the experience of regret and disappointment. Organizational Behavior and Human Decision Processes, 75, 117-141. doi:10.1006/obhd.1998.2784

3) I sometimes feel like I chose the wrong person when I find out about how a previous or potential relationship partner is doing.

4) When I think about how my current relationship is doing, I often assess opportunities I have passed up.

5) I often fantasize about being in a relationship that is quite different than the one I'm currently in. 